\title{
Model Long Side-Chain PPO-Based Anion Exchange Ionomers: \\ Properties and Alkaline Stability
}

\author{
R.-A. Becerra-Arciniegas ${ }^{1,3}$, R. Narducci ${ }^{1}$, G. Ercolani ${ }^{2}$, E. Sgreccia ${ }^{1}$, \\ L. Pasquini ${ }^{3}$, M. L. Di Vona*,1, P. Knauth ${ }^{*, 3}$ \\ ${ }^{1}$ University of Rome Tor Vergata, Dep. Industrial Engineering, and \\ International Associated Laboratory: Ionomer Materials for Energy, 00133 Roma, Italy \\ 2 University of Rome Tor Vergata, Dep. Chemical Sciences and Technologies, 00133 Roma, Italy \\ ${ }^{3}$ Aix Marseille Univ, CNRS, MADIREL (UMR 7246) and International Associated Laboratory: Ionomer \\ Materials for Energy, Campus St Jérôme, 13013 Marseille, France
}

* Corresponding authors: divona@uniroma2.it and philippe.knauth@,univ-amu.fr

\begin{abstract}
The stability of anion exchange membranes is paramount for the use in alkaline fuel cells. Long chain ionomers are supposed to be more alkaline-resistant with respect to short chain isomers. In this paper the synthesis, properties and stability of ionomers with a long side chain are investigated. Poly(2,6-dimethyl-1,4-phenylene)oxide (PPO) is chosen as backbone, due to its reported stability in alkaline conditions. The functional group is pentyl-ammonium with trimethylamine (TMA) or 1,4-diazabicyclo[2.2.2]octane (DABCO) as model amines. The synthesis is carried out via metalation reaction and is optimized as a function of temperature and time. The water uptake is relatively low, in accordance with the large hydrophobicity of the PPO backbone. The through-plane ionic conductivity is consistent with literature data; it amounts to $15.3 \mathrm{mS} / \mathrm{cm}$ at $80{ }^{\circ} \mathrm{C}$ for the TMA derivative. The mechanical properties are typical of ionomers below the glass transition temperature (for the TMA derivative at ambient humidity: Young Modulus $=1310 \pm 30 \mathrm{MPa}$ ). The stability in alkaline conditions, studied by thermogravimetric analysis and measurements of ionic conductivity and ion exchange capacity, is higher than that of short-side chain ionomers with the same basic group. The decrease of ionic conductivity (57 vs $22 \%$ residual conductivity after $72 \mathrm{~h}$ in $2 \mathrm{M} \mathrm{NaOH}$ at $80^{\circ} \mathrm{C}$ ) and IEC is monitored showing that the degradation is fast in the first hours and may by described by second order kinetics. These results help in selecting high performance anion exchange membranes for electrochemical energy technologies.
\end{abstract}




\section{Introduction}

Anion exchange ionomers are used as innovative separators in alkaline membrane fuel cells ${ }^{1-3}$. The major advantage of these devices is that the oxygen reduction reaction (ORR) can be catalysed in alkaline conditions by non-noble metals, such as $\mathrm{Ag}$ or $\mathrm{Ni}^{3-5}$. The use of anion exchange membranes (AEM) avoids the severe carbonation issues observed in alkaline fuel cells with liquid electrolytes. However, the practical application of AEM in fuel cells is hampered by their instability in alkaline environment due to the attack of the ammonium groups by the hydroxide ions ${ }^{6-9}$. Furthermore, the polymer backbone can also be attacked and chain scission processes occur ${ }^{10-11}$. The instability of the widely studied poly(arylene ether sulfones) (PSU) is promoted by the sulfone groups present in the backbone through their inductive effect increasing the reactivity in specific positions ${ }^{13}$. AEM based on poly(2,6-dimethyl-1,4-phenylene oxide) (PPO) ${ }^{11-12}$ are expected to have a higher alkaline stability in comparison with PSU, due to the less activated backbone for a nucleophilic attack ${ }^{12}$.

The alkaline attack may occur by several mechanisms ${ }^{8-9,12}$. The most difficult to avoid is the nucleophilic substitution reaction $\mathrm{S}_{\mathrm{N}} 2$ : the rate of this bimolecular reaction is proportional to the IEC of the ionomer and the $\mathrm{OH}^{-}$concentration in the medium ${ }^{13-14}$. The bimolecular Hofmann elimination $\mathrm{E} 2$ leads to the formation of an alkene. In sterically very unfavourable conditions, the monomolecular elimination reaction E1 can also occur. Various approaches are discussed in the literature to mitigate the alkaline degradation ${ }^{1-2,15-25}$, including a change of the polymer backbone $^{24,26-28}$, the introduction of side chains ${ }^{18,22,29-32}$, the presence of a secondary phase ${ }^{33-35}$, a delocalization of the positive charge ${ }^{7,21}$, or a protection by steric hindrance ${ }^{7,36-37}$.

In this study, we investigate the alkaline stability of model long side-chain anion-conducting ionomers based on PPO with N-pentyl-N,N,N-trimethylammonium side groups, given that the theoretical work of Pivovar and coworkers shows that the most stable side-chain length corresponds to 4-5 $\mathrm{CH}_{2}$ groups ${ }^{30}$. Two model amines, small and flexible trimethylamine (TMA) and bulky and rigid 1,4-diaza-bicyclo[2.2.2] octane (DABCO), are used for functionalization. The water uptake, thermal, mechanical and electrical properties are reported before and after a harsh alkaline treatment in $2 \mathrm{M} \mathrm{NaOH}$ at $80^{\circ} \mathrm{C}$ during various times.

\section{Experimental section}

\section{Materials}

Poly(2,6-dimethyl-1,4-phenylene)oxide (PPO, MW = $50000 \mathrm{~g} / \mathrm{mol}$ ) trimethylamine (TMA, $4.2 \mathrm{M}$ 
in ethanol), 1,4-diazabicyclo[2.2.2] octane (DABCO), n-butyllithium (BuLi, 2,5 $\mathrm{M}$ in hexane), tetrahydrofuran (THF, anhydrous), 1,4-dibromobutane, and N-methyl-2-pyrrolidone (NMP) were reagent-grade, purchased from Sigma-Aldrich.

\section{Ionomer synthesis}

Synthesis of PPO- $\left(\mathrm{CH}_{2}\right)_{5} \mathrm{Br}$.

PPO (5 g, $41.7 \mathrm{meq})$ was dissolved in dry THF $(500 \mathrm{~mL})$ under nitrogen at $55^{\circ} \mathrm{C}$. The solution was cooled to RT and $25 \mathrm{~mL}$ of $\mathrm{n}-\mathrm{BuLi}(2.5 \mathrm{M}, 62.6 \mathrm{meq})$ was added dropwise until the appearance of a persistent light yellow coloration. The reaction was carried out during $3 \mathrm{~h}$ at two temperatures: 25 or $55{ }^{\circ} \mathrm{C}$ in order to optimize the final products (see Results and Discussion). The solution was then cooled to $-70{ }^{\circ} \mathrm{C}$ and 1,4 -dibromobutane $(15 \mathrm{~mL}, 125 \mathrm{meq})$ was added. A light yellow solution was immediately formed and the reaction was kept under stirring overnight at RT. The product was precipitated in ethanol and the yellow polymer was filtered, washed repeatedly with fresh ethanol and dried at $55^{\circ} \mathrm{C}$ during 2 days.

The products were characterized by ${ }^{1} \mathrm{H}$ NMR. The degree of benzyl bromination was 0.24 at 25 ${ }^{\circ} \mathrm{C}$ and 0.35 at $55^{\circ} \mathrm{C}$.

Synthesis of PPO- $\left(\mathrm{CH}_{2}\right)_{5} \mathrm{TMA}$ and PPO- $\left(\mathrm{CH}_{2}\right)_{5} \mathrm{DABCO}$.

The brominated polymer obtained at $55^{\circ} \mathrm{C}$ (degree of benzyl bromination 0.35 ) was dissolved in NMP and the amine was added in excess of 5.5 (TMA) or 1.5 (DABCO) with respect to the degree of functionalization, due to the well-known volatility of TMA. The solution was kept at 80 ${ }^{\circ} \mathrm{C}$ for $72 \mathrm{~h}$ and then the polymer was precipitated in deionized water, filtered, washed with water and dried under vacuum at $60^{\circ} \mathrm{C}$.

Membranes were obtained by casting at $95{ }^{\circ} \mathrm{C}$ from NMP solution $(0.3$ g polymer in $25 \mathrm{~mL}$ solvent).

\section{NMR spectroscopy}

${ }^{1} \mathrm{H}$ NMR spectroscopy was performed using a Bruker Avance 400 apparatus (400.13 MHz) using deuterated solvents $\left(\mathrm{CDCl}_{3}, \mathrm{DMSO}-\mathrm{d}_{6}\right)$. Chemical shifts were referenced to tetramethylsilane.

\section{Ion exchange capacity}

The IEC was determined by NMR spectroscopy (see Results) and by Mohr titration. For the Mohr titration, the chloride form was obtained by treating the AEM in $1 \mathrm{M} \mathrm{NaCl}$ solution during 
$24 \mathrm{~h}$. The membranes were then washed carefully with deionized water to remove any excess $\mathrm{NaCl}$. The $\mathrm{Cl}^{-}$anions contained in the membranes were exchanged with $\mathrm{SO}_{4}^{2-}$ by immersion in 1 $\mathrm{M} \mathrm{Na}_{2} \mathrm{SO}_{4}$ solution for $24 \mathrm{~h}$. This solution was titrated using $0.02 \mathrm{M} \mathrm{AgNO}_{3}$. The end-point indicator was prepared dissolving $1 \mathrm{~g}$ of $\mathrm{K}_{2} \mathrm{CrO}_{4}$ in $20 \mathrm{~mL}$ of water.

By Mohr titration, PPO- $\left(\mathrm{CH}_{2}\right)_{5}$-TMA had an IEC $=1.8 \mathrm{meq} / \mathrm{g}$ and PPO- $\left(\mathrm{CH}_{2}\right)_{5}-\mathrm{DABCO}$ an $\mathrm{IEC}=1.3 \mathrm{meq} / \mathrm{g}$.

\section{Water uptake}

The membrane mass was measured after $24 \mathrm{~h}$ immersion in deionized water at $25^{\circ} \mathrm{C}$, removing excess surface water by rapid blotting with absorbent paper $\left(m_{\text {wet }}\right)$. The dry mass was obtained after drying in a desiccator over $\mathrm{P}_{2} \mathrm{O}_{5}$ during $72 \mathrm{~h}\left(m_{d y}\right)$. The water uptake WU was calculated according to the equation:

$$
W U=100 \cdot \frac{m_{w e t}-m_{d r y}}{m_{d r y}}
$$

The hydration numbers $\lambda$, which are the number of water molecules per ammonium group, are calculated using the IEC of the ionomer according to the equation:

$$
\lambda=\frac{10 \cdot W U}{M\left(H_{2} O\right) \cdot I E C}
$$

$\mathrm{M}\left(\mathrm{H}_{2} \mathrm{O}\right)$ is the molar mass of water.

\section{Ionic conductivity}

Prior to the measurements, the membrane samples were immersed during $24 \mathrm{~h}$ in $2 \mathrm{M} \mathrm{NaCl}(\mathrm{Cl}$ form) or $2 \mathrm{M} \mathrm{NaOH}$ (OH form) solution and then thoroughly washed in deionized water. In the latter case, the solution was kept under nitrogen to avoid contamination by $\mathrm{CO}_{2}$. The ionic conductivity was measured between 25 and $80{ }^{\circ} \mathrm{C}$ by impedance spectroscopy using a Biologic VSP300 equipment. The frequency range was between $1 \mathrm{~Hz}$ and $6 \mathrm{MHz}$ and the a.c. voltage amplitude was $20 \mathrm{mV}$. The measurements were made on fully humidified samples in two-point through-plane configuration using a swagelok cell with electrode area $A=0.264 \mathrm{~cm}^{2}$. The membrane resistance $\mathrm{R}$ was determined at the intersection of the electrode arc with the real axis. The membrane thickness d was determined before and after the measurements using a Mitutuyo micrometer.

The ionic conductivity was calculated according to the equation: 


$$
\sigma=\frac{d}{R \cdot A}
$$

Mechanical measurements

The tensile stress-strain measurements were performed on membranes in $\mathrm{Cl}$ form using an ADAMEL Lhomargy DY30 apparatus at room temperature and ambient humidity ((50 +/- 10) $\% \mathrm{RH}$ ) or at full humidification.

\section{Thermogravimetry}

High-resolution thermogravimetric analysis of membranes ( $\mathrm{Cl}$ form) was made using a TA Q500 apparatus. The samples were placed in Pt sample holders. The experiments were perfomed in air flux between 50 and $600{ }^{\circ} \mathrm{C}$. The maximum heating rate was $3 \mathrm{~K} / \mathrm{min}$. 


\section{Results and Discussion}

\section{Synthesis}

Figure 1a shows the molecular formulas of long side-chain ionomers functionalized by TMA and DABCO. Butyllithium may attack PPO protons on two different positions in the side chain or in the main chain leading to the formation of a benzyl (A) or an aryl (B) carbanion (Figure 1b). The following reaction with 1,4-dibromobutane gives the bromine derivatives in benzylic or arylic position. The distribution of the products depends on the temperature and time. In our case, the time was fixed at $3 \mathrm{~h}$ while the temperature was varied $\left(25\right.$ or $\left.55^{\circ} \mathrm{C}\right)$. At low temperature the ratio $\mathrm{A}: \mathrm{B}$ (Figure $1 \mathrm{~b}$ ) was 2.4:1, while at higher temperature the ratio was 8.8:1. These data correspond to a competitive reaction under thermodynamic or kinetic control ${ }^{38}$. The substitution at benzylic position appears to be more favored than that at the aromatic ring position under both kinetic and thermodynamic control, although a larger selectivity is observed under thermodynamic control. The larger stability of the benzyl anion can be ascribed to resonance delocalization of the negative charge that is not allowed for the sp2 centered aryl anion.

a)

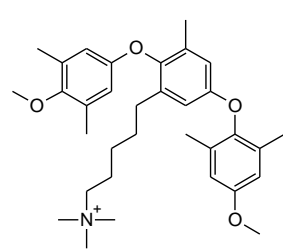

PPO- $\left(\mathrm{CH}_{2}\right)_{5}$ TMA

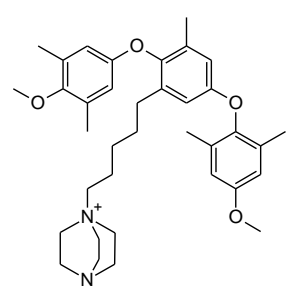

PPO- $\left(\mathrm{CH}_{2}\right)_{5} \mathrm{DABCO}$

b)

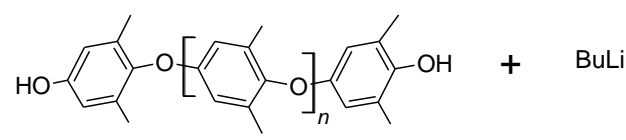

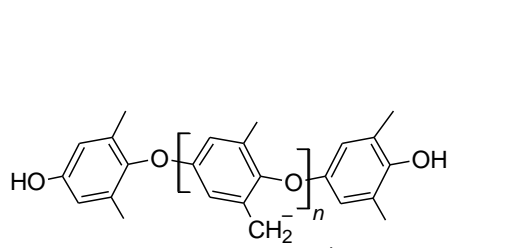

A

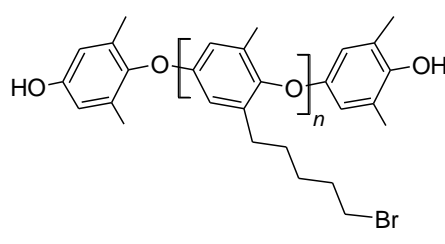

PPO-Br (benzylic position)

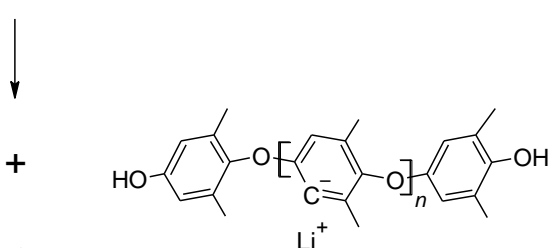

B

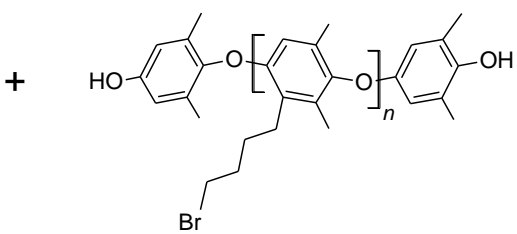

$\mathrm{PPO}-\mathrm{Br}$ (arylic position)

Figure 1. a) Molecular formulas of long side-chain anion exchange polymers (substitution in benzylic position); b) reaction pathways for the synthesis of brominated PPO. 
The ${ }^{1} \mathrm{H}$ NMR spectra of the brominated derivatives obtained at the two temperatures are shown in Figure 2.

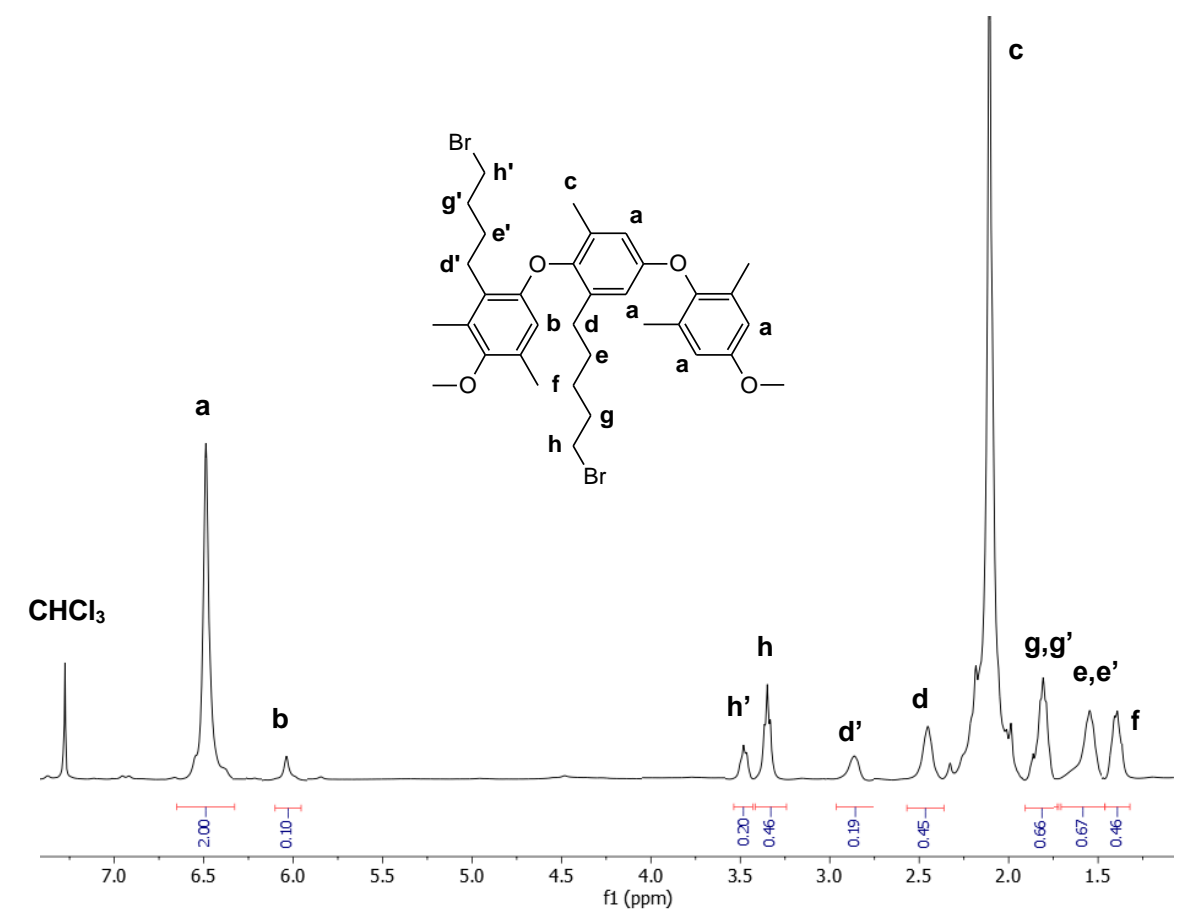

b)

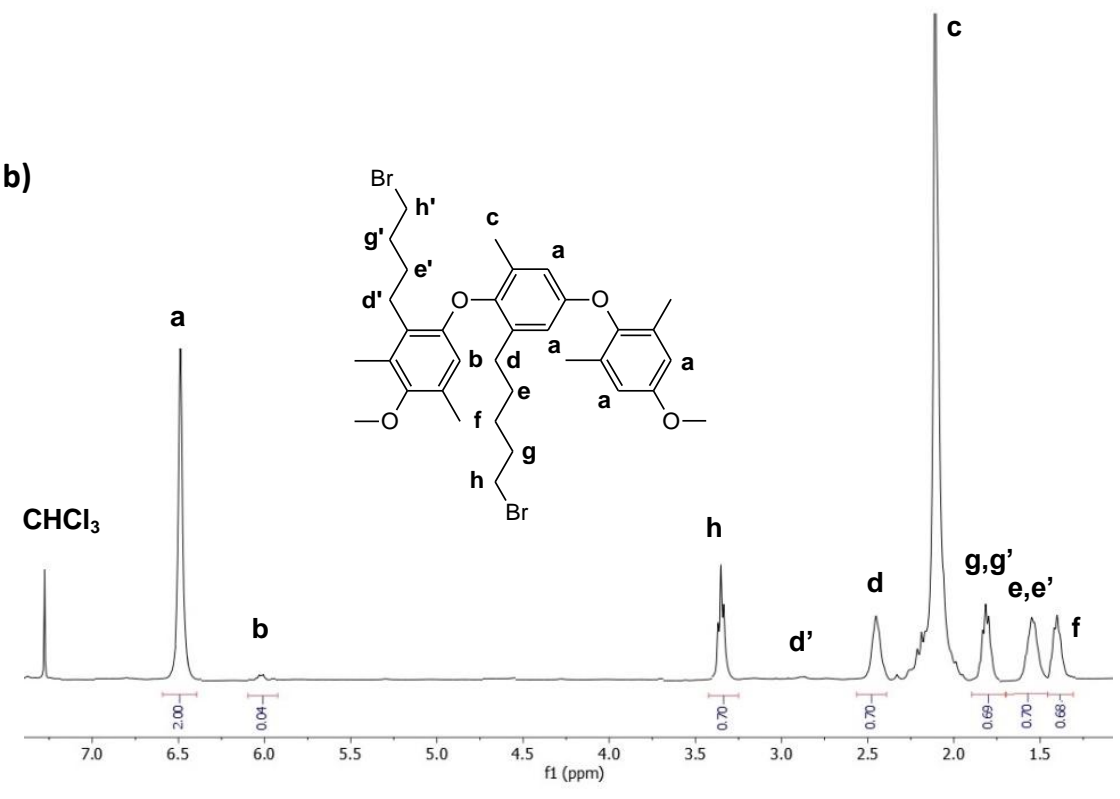

Figure 2. ${ }^{1} \mathrm{H}$ NMR spectra of PPO- $\left(\mathrm{CH}_{2}\right)_{5} \mathrm{Br}$ in $\mathrm{CDCl}_{3}$ obtained at a) $25^{\circ} \mathrm{C}$ and b) $55^{\circ} \mathrm{C}$.

The presence of the substitution of alkylbromine in aryl position is evidenced by the signal of the hydrogen $b$ (1H, $6.03 \mathrm{ppm})$, which appears with higher intensity in the reaction carried out at 25 
${ }^{\circ} \mathrm{C}$ (Figure 2a). The signals of the methylene group in $\alpha$ to bromine $(2 \mathrm{H}, b$ and $h)$ appear at 3.34 ppm for the benzyl derivative and at $3.48 \mathrm{ppm}$ for the aryl one ${ }^{39}$. The latter signal is not observable in the spectrum of the compound obtained at higher temperature (Figure 2b) due to the lower quantity of the aryl substitution. The integration of the signal $f(2 \mathrm{H}, 1.40 \mathrm{ppm})$, present only in the derivative obtained from the attack in benzylic position (about 90\% of the peaks $h$ and $h$ ', Figure 2b), confirms that a part of the product is due to the formation of the aryl (B) carbanion (Figure 1b). The total degree of bromination DBr is calculated from the integration of the protons $b$ and $b$ ' with respect to the protons $a$ of PPO; $\mathrm{DBr}$ amounts to 0.34 and 0.39 at 25 and $55^{\circ} \mathrm{C}$ respectively.

The reaction with tertiary amines was conducted only with the derivative obtained at higher temperature.

Figure $3 \mathrm{a}$ shows the ${ }^{1} \mathrm{H}$ NMR spectrum of PPO- $\left(\mathrm{CH}_{2}\right)_{5}$-TMA. The peak $a$ is assigned to the hydrogens $(2 \mathrm{H})$ of the aromatic ring containing the pentyl chain originating from the attack of BuLi in benzylic position. The attack on the aryl moiety generates the signal $b$ (approximatively $4 \%$ ). The peak $b$ is not integrable in the case of PPO- $\left(\mathrm{CH}_{2}\right)_{5}-\mathrm{DABCO}$ (Figure $3 \mathrm{~b}$ ). The degree of amination (DAM) of PPO- $\left(\mathrm{CH}_{2}\right)_{5}$ TMA is obtained from the integration of the aromatic hydrogens of PPO $(a, 2 \mathrm{H})$, the hydrogens of methyl groups on the ammonium ions $(i, 9 \mathrm{H})$, and the internal hydrogens of the pentyl chain $(e, f, g 6 \mathrm{H})$ resulting in 0.28 . The other signals overlap with the solvents (DMSO, $\mathrm{H}_{2} \mathrm{O}$ ). The spectrum of PPO- $\left(\mathrm{CH}_{2}\right)_{5}-\mathrm{DABCO}$ is more complex. The peak $l$ due to hydrogens in $\alpha$ to the nitrogen are shifted to highfield with respect to hydrogens near to the quaternary nitrogen ( $i$ ) and overlap with the signals $b$ of the $\mathrm{CH}_{2}$ belonging to the pentyl chain. The integration of NMR peaks $e, f, g$ of the DABCO derivative shows the absence of crosslinks in spite of the two amine groups in the molecule ${ }^{24}$. 

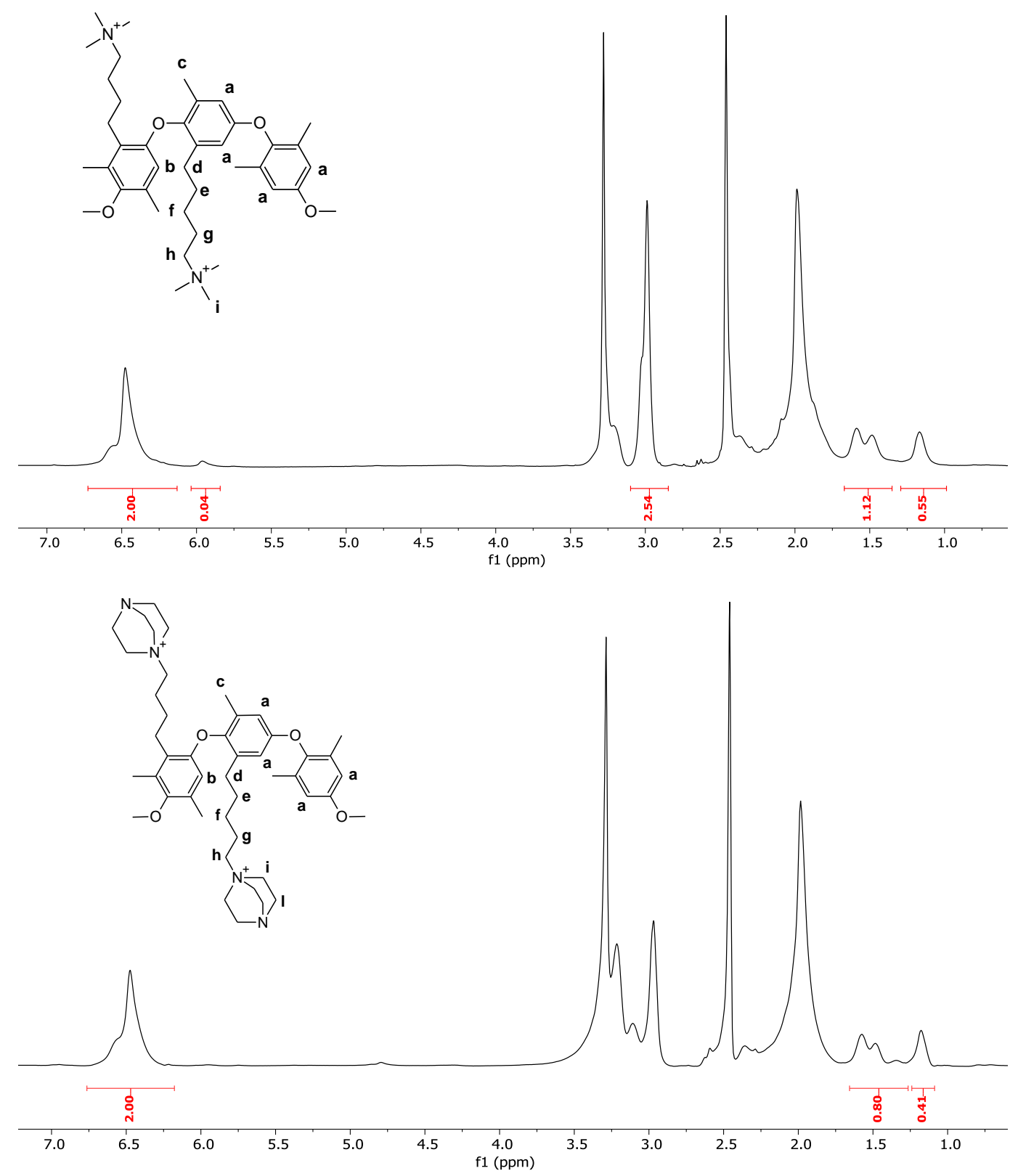

Figure 3. ${ }^{1} \mathrm{H}$ NMR spectra of (a) PPO- $\left(\mathrm{CH}_{2}\right)_{5}$-TMA with DAM $=0.28$ and (b) PPO- $\left(\mathrm{CH}_{2}\right)_{5^{-}}$ DABCO with DAM $=0.20$ in DMSO d d $_{6}$

The DAM is lower for DABCO showing a lower reaction yield probably due to the more bulky molecule that reduces the $\mathrm{S}_{\mathrm{N}} 2$ reaction rate by steric hindrance. The IEC obtained from NMR using eq. 4 is $1.8 \mathrm{meq} / \mathrm{g}$ for TMA and $1.3 \mathrm{meq} / \mathrm{g}$ for DABCO in good agreement with the values obtained by Mohr titration (see experimental).

$$
D A M=\frac{I E C \times M_{P P O}}{1-I E C \times M_{\left(\mathrm{CH}_{2}\right)_{4} T M A \text { or }\left(\mathrm{CH}_{2}\right)_{4} \mathrm{DABCO}}}
$$


DAM, $M_{P P O}=120 \mathrm{~g} / \mathrm{mol}$ and $M_{\left(\mathrm{CH}_{2}\right)_{4} \text { TMA or }\left(\mathrm{CH}_{2}\right)_{4} \text { DABCO }}=115$ or $168 \mathrm{~g} / \mathrm{mol}$ are respectively the degree of amination, the molar mass of the polymer backbone and the molar mass of the functional unit, which contains $4 \mathrm{CH}_{2}$ groups given that one $\mathrm{CH}_{2}$ belongs to the PPO structure.

\section{Properties}

The water uptake and ion conductivity values of PPO- $\left(\mathrm{CH}_{2}\right)_{5}-\mathrm{TMA}$ and PPO- $\left(\mathrm{CH}_{2}\right)_{5}-\mathrm{DABCO}$ are reported in Table 1. The water uptake values are relatively low in comparison with PSU-based ionomers ${ }^{14,40}$, certainly due to the very hydrophobic PPO backbone, known to exhibit the lowest water sorption among engineering plastics ${ }^{41}$, and increase relatively little with temperature. The room temperature data are consistent with similar PPO-based ionomers ${ }^{42-43}$. The hydration numbers are comparable with literature data for cross-linked copolymers ${ }^{11}$, but clearly above ionomers made by a bromination route and with very long side chains ${ }^{16}$. The higher hydration numbers for the $\mathrm{DABCO}$ derivative might be attributed to the larger volume of the $\mathrm{DABCO}$ molecule increasing the inter-chain space.

The conductivity data are comparable with recent literature ${ }^{43-44}$. They are also consistent with the conductivity reported at room temperature for sulfonated PPO with an IEC $=2.63 \mathrm{meq} / \mathrm{g}(12$ $\mathrm{mS} / \mathrm{cm}^{41}$ ), considering the lower mobility of hydroxide (at infinite dilution in water: $20.510^{-5} \mathrm{~cm}^{2}$ $\left.\mathrm{s}^{-1} \mathrm{~V}^{-1}\right)^{45-46}$ vs. hydronium ions $\left(36.310^{-5} \mathrm{~cm}^{2} \mathrm{~s}^{-1} \mathrm{~V}^{-1}\right)^{45-46}$. The ion conductivity of the $\mathrm{Cl}$ form is below the $\mathrm{OH}$ form due to the lower mobility of the chloride ion (at infinite dilution in water: 7.9 $\left.10^{-5} \mathrm{~cm}^{2} \mathrm{~s}^{-1} \mathrm{~V}^{-1}\right)^{45-46}$. The higher values for the TMA derivative are consistent with its higher IEC. The activation energy of conductivity calculated for the $\mathrm{OH}$ form of PPO- $\left(\mathrm{CH}_{2}\right)_{5}$-TMA and PPO- $\left(\mathrm{CH}_{2}\right)_{5}$-DABCO are 0.11 and $0.13 \mathrm{eV}$, respectively, consistent with a conduction mechanism through hydrated channels ${ }^{11}$. The activation energy for the $\mathrm{Cl}$ forms is higher $(0.2$ $\mathrm{eV}$ ) in agreement with the expectation and the literature for halide ion conductors ${ }^{11,47}$. 
Table 1. Ion conductivity $\sigma$, water uptake WU and hydration number $\lambda$ of PPO- $\left(\mathrm{CH}_{2}\right)_{5}-\mathrm{TMA}$ $(\mathrm{IEC}=1.8 \mathrm{meq} / \mathrm{g})$ and $\mathrm{PPO}-\left(\mathrm{CH}_{2}\right)_{5}-\mathrm{DABCO}(\mathrm{IEC}=1.3 \mathrm{meq} / \mathrm{g})$.

\begin{tabular}{|c|c|c|c|c|c|c|c|c|c|c|c|c|}
\hline & & \multicolumn{5}{|c|}{ PPO- $\left(\mathrm{CH}_{2}\right)_{5}-\mathrm{TMA}$} & \multicolumn{6}{|c|}{ PPO- $\left(\mathrm{CH}_{2}\right)_{5}-\mathrm{DABCO}$} \\
\hline $\begin{array}{c}\mathrm{T} \\
/{ }^{\circ} \mathrm{C}\end{array}$ & $\begin{array}{l}\sigma(\mathrm{OH}) / \\
\mathrm{mS} \mathrm{cm}^{-1}\end{array}$ & $\begin{array}{c}\mathrm{WU}(\mathrm{OH}) \\
\quad / \%\end{array}$ & $\lambda(\mathrm{OH})$ & $\begin{array}{c}\sigma(\mathrm{Cl}) / \\
\mathrm{mS} \mathrm{cm}{ }^{-1}\end{array}$ & $\begin{array}{c}\mathrm{WU}(\mathrm{Cl}) \\
\quad / \%\end{array}$ & $\lambda(\mathrm{Cl})$ & $\begin{array}{l}\sigma(\mathrm{OH}) / \\
\mathrm{mS} \mathrm{cm}^{-1}\end{array}$ & $\begin{array}{c}\mathrm{WU}(\mathrm{OH}) \\
\quad / \%\end{array}$ & $\lambda(\mathrm{OH})$ & $\begin{array}{l}\sigma(\mathrm{Cl}) / \\
\mathrm{mS} \mathrm{cm}^{-1}\end{array}$ & $\begin{array}{c}\mathrm{WU}(\mathrm{Cl}) \\
/ \%\end{array}$ & $\lambda(\mathrm{Cl})$ \\
\hline 25 & 8.4 & 47.8 & 14.7 & 1.9 & 20.2 & 6.2 & 4.3 & 49.8 & 21.3 & 1.4 & 21.0 & 9.0 \\
\hline 45 & 8.9 & 53.0 & 16.3 & 3.3 & 25.1 & 7.7 & 5.3 & - & - & 2.0 & - & - \\
\hline 60 & 12.9 & - & - & 5.5 & 31.0 & 9.6 & 7.8 & 56.1 & 24.0 & 3.1 & - & - \\
\hline 80 & 15.3 & 58.8 & 18.1 & 9.3 & 36.0 & 11.1 & 9.6 & 62.5 & 26.7 & 4.7 & 36.1 & 15.4 \\
\hline
\end{tabular}

Typical mechanical tensile stress-strain test curves for membranes in $\mathrm{Cl}$ form are shown in Figure 4. One notices a very good reproducibility, especially for PPO- $\left(\mathrm{CH}_{2}\right)_{5}$-TMA. The average mechanical properties are reported for the two polymers in Table 2 . They are comparable to the properties of other aromatic polymer electrolytes ${ }^{7,35,48-50}$ and are typical of stiff ionomers below their glass transition temperature. The glass transition temperature of pristine PPO is known to be very high $\left(212^{\circ} \mathrm{C}\right)^{41}$. The Young modulus is above $1 \mathrm{GPa}$ at ambient humidity, related to the high stiffness and strength of pristine PPO (2.55 GPa and $63.4 \mathrm{MPa}$, respectively $\left.{ }^{41}\right)$ weakened by the introduction of the ionic groups that attract water molecules, as observed in all ionomers ${ }^{51}$. The high dielectric constant of water reduces the Van der Waals forces between the macromolecular chains, mainly attributed to dipole-dipole interactions of the benzene rings ${ }^{41}$, which are probed in the elastic domain. The lower Young modulus and yield stress at $100 \% \mathrm{RH}$ is consistent with the plasticizing effect of water. The low elongation at break of all samples, irrespective of the water content, is in the order of magnitude of similar ionomers ${ }^{48}$. The yield stress and tensile strength are much lower for the DABCO derivative, which is attributable to the large and rigid DABCO molecule, which increases the distance between macromolecular chains, enabling larger hydration numbers and weakening the Van der Waals forces between chains, as discussed above. 


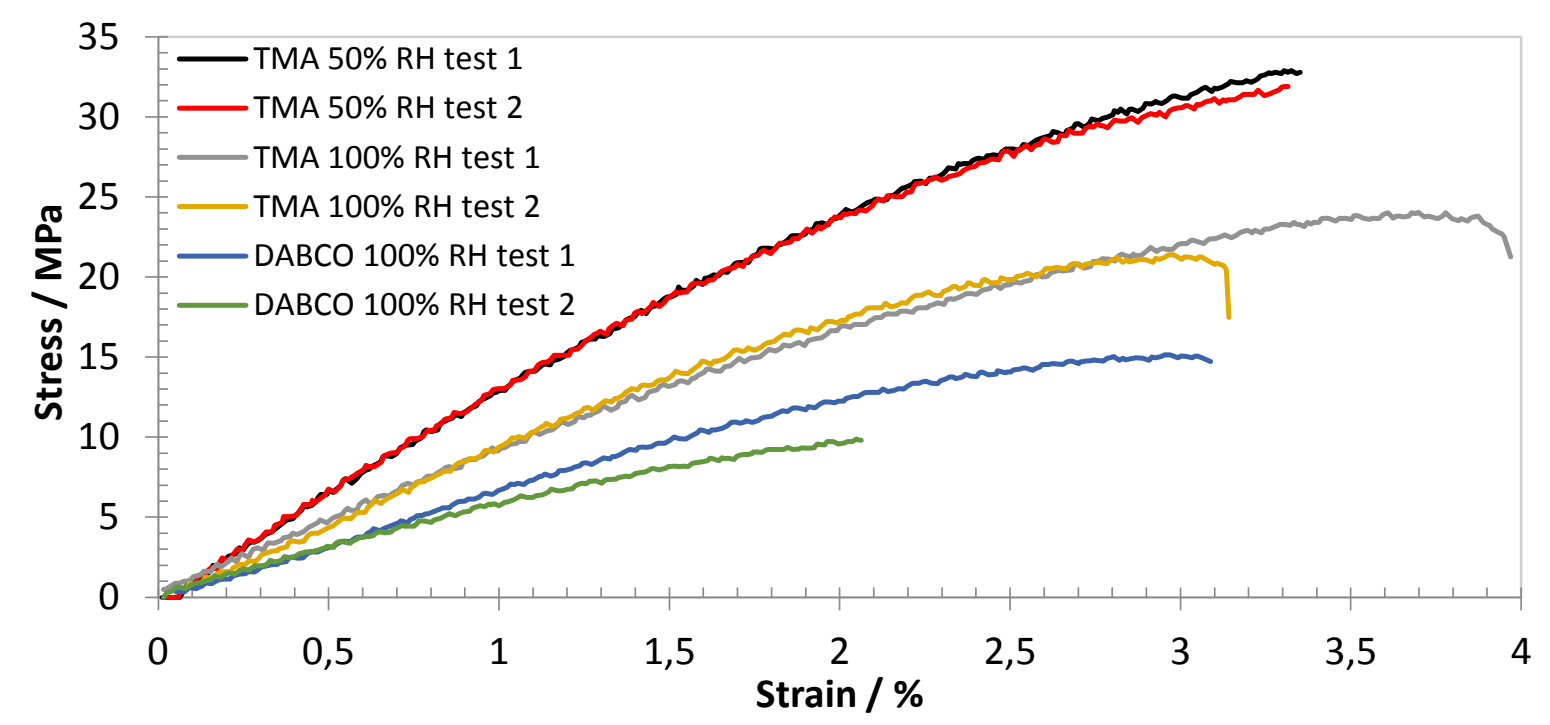

Figure 4. Tensile stress-strain curves of membranes $(\mathrm{Cl}$ form $)$ at $25^{\circ} \mathrm{C}$ at $\mathrm{RH}=(50 \pm 10) \%$ and fully humidified $(\mathrm{RH}=100 \%)$.

Table 2. Average mechanical properties of PPO- $\left(\mathrm{CH}_{2}\right)_{5}$-TMA and PPO- $\left(\mathrm{CH}_{2}\right)_{5}-\mathrm{DABCO}$ : Young modulus E, yield stress YS and elongation at break $\varepsilon$.

\begin{tabular}{ccccc}
\hline Sample & $\mathrm{RH} / \%$ & $\mathrm{E} / \mathrm{MPa}$ & $\mathrm{YS} / \mathrm{MPa}$ & $\varepsilon / \%$ \\
\hline PPO- $\left(\mathrm{CH}_{2}\right)_{5}$-TMA & 50 & $1310 \pm 30$ & $28.4 \pm 0.3$ & $3.3 \pm 0.1$ \\
& 100 & $820 \pm 60$ & $16.2 \pm 3.4$ & $3.5 \pm 0.4$ \\
PPO- $\left(\mathrm{CH}_{2}\right)_{5}$-DABCO & 100 & $730 \pm 140$ & $4.2 \pm 0.8$ & $2.5 \pm 0.5$ \\
\hline
\end{tabular}

\section{Alkaline stability}

The thermal behavior of AEM is investigated by high-resolution thermogravimetric analysis before and after a degradation treatment during $168 \mathrm{~h}$ in $2 \mathrm{M} \mathrm{NaOH}$ at $80{ }^{\circ} \mathrm{C}$ (Figure $5 \mathrm{a}$ and b). Figure $5 \mathrm{a}$ shows the mass loss and Figure $5 \mathrm{~b}$ the derivative thermograms. The peaks correspond to the principal mass loss phenomena. In pristine PPO- $\left(\mathrm{CH}_{2}\right)_{5}-\mathrm{TMA}$, the large peak around 200 ${ }^{\circ} \mathrm{C}$ can be attributed to the loss of TMA; the mass loss of about $12 \%$, integrated between 160 and $230{ }^{\circ} \mathrm{C}$, is in good agreement with the degree of functionalization of 0.28 (corresponding to $11 \%)$. This asymmetric peak is significantly reduced after the alkaline treatment. The mass loss, integrated over the same temperature range, is $8 \%$, corresponding to a decrease of the 
ammonium groups by about $40 \%$, In PPO- $\left(\mathrm{CH}_{2}\right)_{5}-\mathrm{DABCO}$, the loss of DABCO (red curves) is observed at a slightly higher temperature around $230^{\circ} \mathrm{C}$.

The second peak at $365^{\circ} \mathrm{C}$ (starting around $300^{\circ} \mathrm{C}$ ) in the pristine ionomers is the trace of the decomposition of methyl and pentyl groups. Considering the degree of functionalization of the ionomers, the mass loss should be $27 \%$ for TMA and 25\% for DABCO in good agreement with the experiment. The very similar broad mass loss centered around $415^{\circ} \mathrm{C}$ for PPO- $\left(\mathrm{CH}_{2}\right)_{5}-\mathrm{TMA}$ and PPO- $\left(\mathrm{CH}_{2}\right)_{5}$-DABCO can be attributed to the decomposition of partially oxidized and crosslinked PPO, as shown previously ${ }^{52-53}$. The main-chain of PPO rearranges on heating in the degradation step, accompanied by the formation of $\mathrm{C}-\mathrm{C}$ bonds, followed by the thermal degradation of the methylene bridges ${ }^{41}$. After the alkaline treatment, the PPO degradation shows instead a sharp double peak around $410^{\circ} \mathrm{C}$. Similar observations were reported previously ${ }^{13}$.

a)

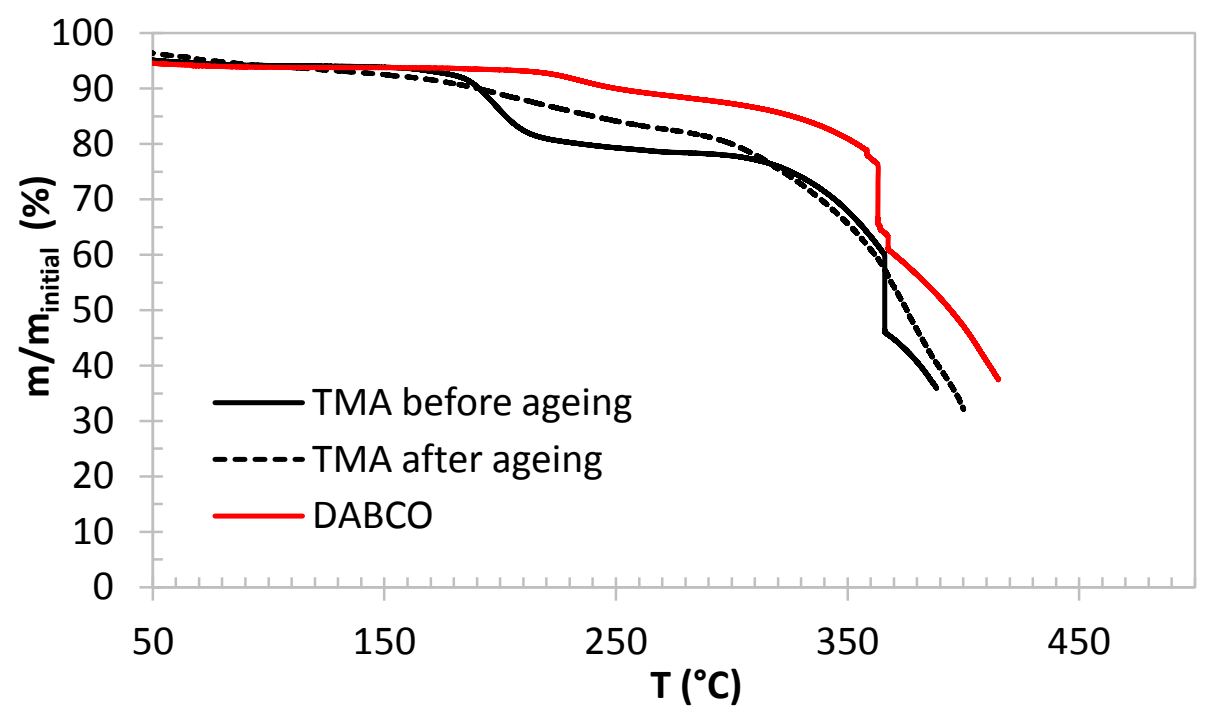


b)

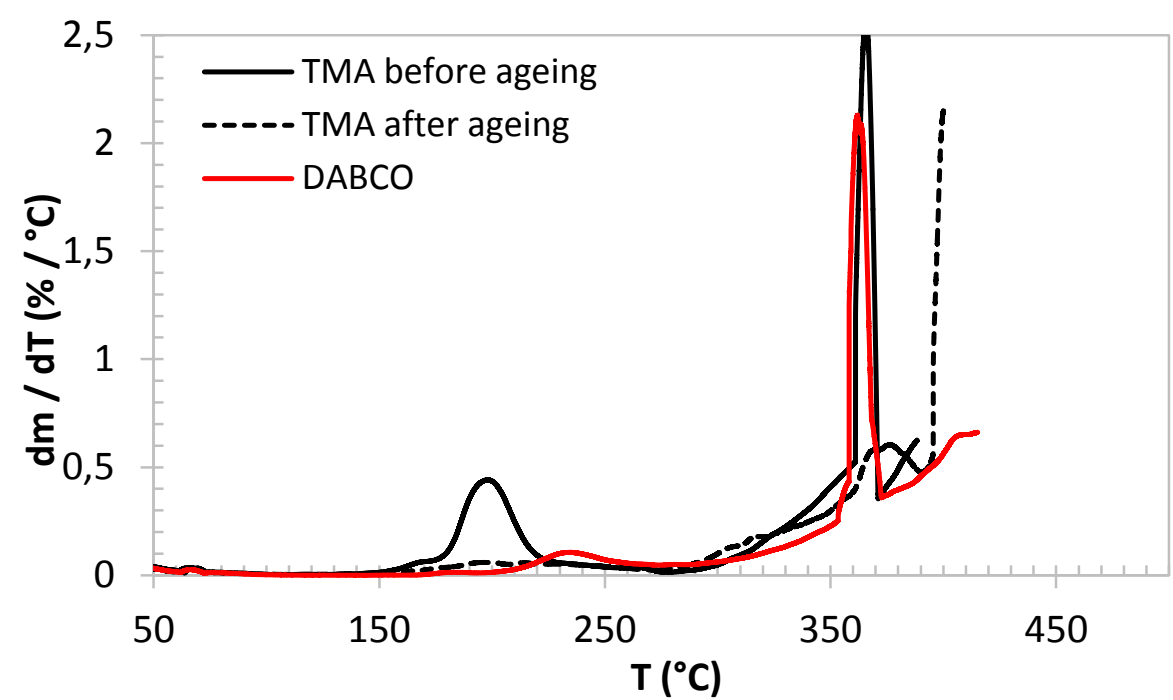

Figure 5. High-resolution thermogravimetric curves of PPO- $\left(\mathrm{CH}_{2}\right)_{5}-\mathrm{TMA}(\mathrm{Cl}$ form) before and after alkaline degradation in $2 \mathrm{M} \mathrm{NaOH}$ at $80^{\circ} \mathrm{C}$ during $168 \mathrm{~h}$ and PPO- $\left(\mathrm{CH}_{2}\right)_{5}-\mathrm{DABCO}(\mathrm{Cl}$ form). a) Mass loss curves, b) derivative curves.

Figure 6 presents the decrease of the ionic conductivity of PPO- $\left(\mathrm{CH}_{2}\right)_{5}$-TMA and PPO- $\left(\mathrm{CH}_{2}\right)_{5^{-}}$ $\mathrm{DABCO}$ with the time of the alkaline treatment. Furthermore, the decrease of the IEC of PPO$\left(\mathrm{CH}_{2}\right)_{5}$-TMA is represented. Inside the experimental uncertainty, the IEC and conductivity data are in qualitative agreement, showing a rapid degradation during the first hours and a slower kinetics at longer times. Both observations can be reconciled with the kinetics of second order reactions, such as $\mathrm{S}_{\mathrm{N}} 2$ or $\mathrm{E} 2$, which are both possible given the presence of a $\beta$-hydrogen in the long side-chain AEM. 


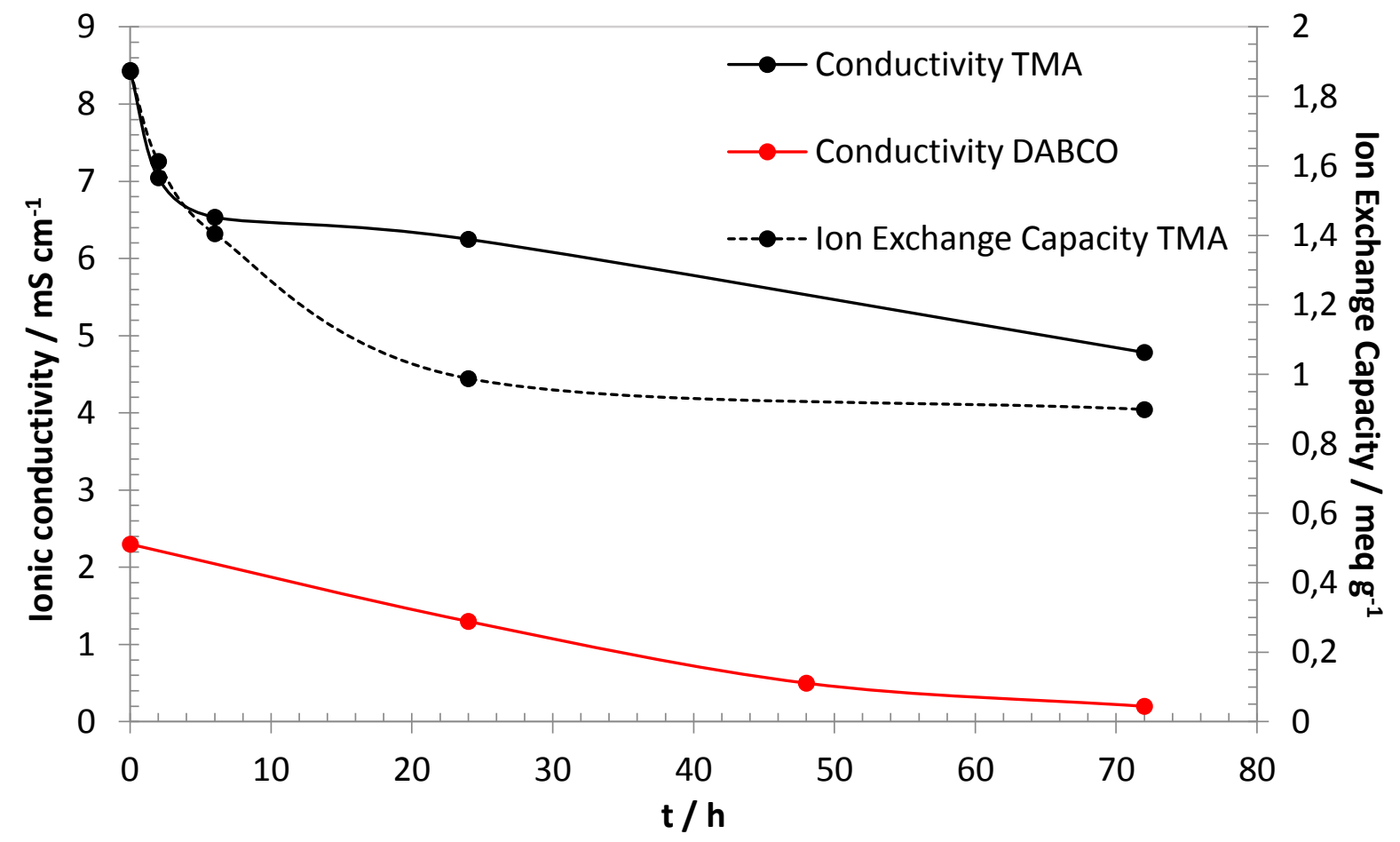

Figure 6. Ionic conductivity of PPO- $\left(\mathrm{CH}_{2}\right)_{5}-\mathrm{TMA}$ and PPO- $\left(\mathrm{CH}_{2}\right)_{5}-\mathrm{DABCO}$ and ion exchange capacity (IEC) of PPO- $\left(\mathrm{CH}_{2}\right)_{5}$-TMA as function of the degradation time in $2 \mathrm{M} \mathrm{NaOH}$ at $80{ }^{\circ} \mathrm{C}$.

For PPO- $\left(\mathrm{CH}_{2}\right)_{5}-\mathrm{DABCO}$, the alkaline degradation is continuous, showing that the bulky and rigid side group does not improve the alkaline stability, different from the results in short side chain ionomers ${ }^{13}$.

In the literature ${ }^{18}$, a low degradation was reported for a similar long side chain PPO- $\left(\mathrm{CH}_{2}\right)_{5}$-TMA in $1 \mathrm{M} \mathrm{NaOH}$; although we do not confirm this result completely, the degradation is anyway much lower than for the corresponding short side chain PPO-TMA ionomer ${ }^{13}$, as shown in the normalized conductivity plot represented in Figure 7. The higher degradation rate observed in this work is certainly also related to the higher $\mathrm{NaOH}$ concentration, which is a parameter of the rate of second order reactions. 


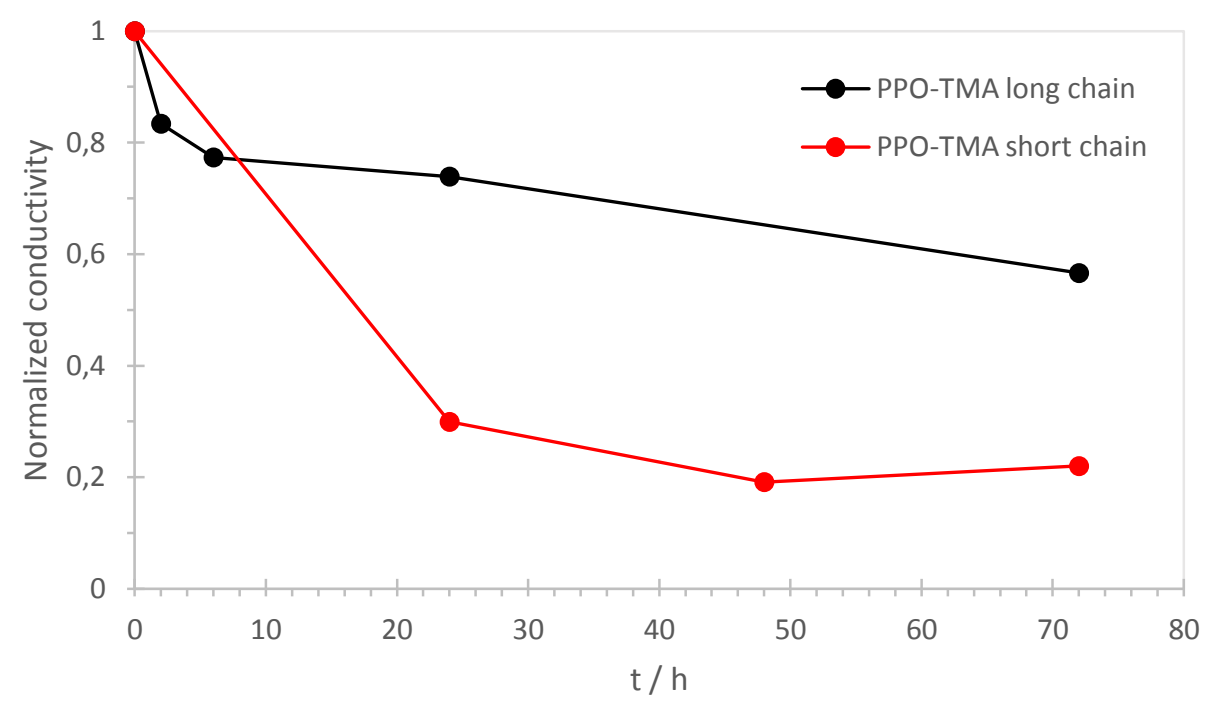

Figure 7. Normalized conductivity dependence on the time of alkaline treatment in $2 \mathrm{M} \mathrm{NaOH}$ at $80^{\circ} \mathrm{C}$ for long and short side-chain $\mathrm{AEM}^{13}$.

The improvement of stability for the long-chain sample is evident in Figure 7; the spacer concept ${ }^{54}$ is verified. Several hypothesis explaining the better stability can be formulated: i) the $\mathrm{S}_{\mathrm{N}} 2$ reaction is less effective, because the primary alkyl halide presents a more than two order of magnitude lower reactivity than the benzyl halide ${ }^{55}$; ii) the ether linkage in the backbone is less destabilized due to the long alkyl chain that screens the positive charge of the ammonium group; iii) the antiperiplanar conformation needed for the $\mathrm{E} 2$ reaction is less stable when a long chain is attached to ammonium ${ }^{30}$. A simple conformational analysis by Newman projections confirms this result.

\section{Conclusions}

Anion exchange membranes based on PPO with a pendant side chain functionalized with TMA or $\mathrm{DABCO}$ are synthetized using a metalation route. The optimization of the reaction conditions allows obtaining ionomers with the pendant groups in benzylic position, which is the thermodynamically favoured product.

The properties and alkaline stability are investigated by several techniques. Stress-strain tests are typical of stiff polymers below their glass transition temperature. The water uptake is lower than that of PSU-based ionomers, but comparable with short side chain PPO. The DABCO derivative presents a higher water uptake due to the bulky molecule. The ionic conductivity and its activation energy are consistent with the mobility of the conducting ions. 
The stability in alkaline condition, studied by thermogravimetry, ion conductivity and IEC measurements, is clearly improved vs. short side chain ionomers. The alkaline degradation is rapid during the first hours of the reaction and shows a slower kinetics at longer times. Both observations can be reconciled with the kinetics of second order reactions, such as $\mathrm{S}_{\mathrm{N}} 2$ or E2.

\section{Acknowledgment}

There is no financial support from funding institutions to be acknowledged. 


\section{References}

1. Merle, G.; Wessling, M.; Nijmeijer, K., Anion exchange membranes for alkaline fuel cells: A review. J. Membr. Sci. 2011, 377, 1-35.

2. $\quad$ Couture, G.; Alaaeddine, A.; Boschet, F.; Ameduri, B., Polymeric materials as anion-exchange membranes for alkaline fuel cells. Progress in Polymer Science 2011, 36, 1521-1557.

3. Hickner, M. A.; Herring, A. M.; Coughlin, E. B., Anion Exchange Membranes: Current Status and Moving Forward. Journal of Polymer Science Part B-Polymer Physics 2013, 51, 1727-1735.

4. Pan, Z. F.; An, L.; Zhao, T. S.; Tang, Z. K., Advances and challenges in alkaline anion exchange membrane fuel cells. Prog. Energy Combust. Sci. 2018, 66, 141-175.

5. Arges, C. G.; Zhang, L., Anion Exchange Membranes' Evolution toward High Hydroxide Ion Conductivity and Alkaline Resiliency. Acs Applied Energy Materials 2018, 1, 2991-3012.

6. $\quad$ Arges, C. G.; Wang, L. H.; Parrondo, J.; Ramani, V., Best Practices for Investigating Anion Exchange Membrane Suitability for Alkaline Electrochemical Devices: Case Study Using Quaternary Ammonium Poly(2,6-dimethyl 1,4-phenylene)oxide Anion Exchange Membranes. J. Electrochem. Soc. 2013, 160, F1258-F1274.

7. Di Vona, M. L.; Narducci, R.; Pasquini, L.; Pelzer, K.; Knauth, P., Anion-conducting ionomers: Study of type of functionalizing amine and macromolecular cross-linking. Int. J. Hydrogen Energy 2014, 39, 14039-14049.

8. Sun, Z.; Pan, J.; Guo, J. N.; Yan, F., The Alkaline Stability of Anion Exchange Membrane for Fuel Cell Applications: The Effects of Alkaline Media. Advanced Science 2018, 5, 11.

9. Nunez, S. A.; Hickner, M. A., Quantitative H-1 NMR Analysis of Chemical Stabilities in AnionExchange Membranes. Acs Macro Letters 2013, 2, 49-52.

10. Miyanishi, S.; Yamaguchi, T., Ether cleavage-triggered degradation of benzyl alkylammonium cations for polyethersulfone anion exchange membranes. Physical Chemistry Chemical Physics 2016, 18, 12009 12023.

11. Pandey, T. P.; Sarode, H. N.; Yang, Y. T.; Yang, Y.; Vezzu, K.; Di Noto, V.; Seifert, S.; Knauss, D. M.; Liberatore, M. W.; Herring, A. M., A Highly Hydroxide Conductive, Chemically Stable Anion Exchange Membrane, Poly(2,6 dimethyl 1,4 phenylene oxide)-b-Poly(vinyl benzyl trimethyl ammonium), for Electrochemical Applications. J. Electrochem. Soc. 2016, 163, H513-H520.

12. Cheng, J.; He, G. H.; Zhang, F. X., A mini-review on anion exchange membranes for fuel cell applications: Stability issue and addressing strategies. International Journal of Hydrogen Energy 2015, 40, 73487360.

13. Becerra-Arciniegas, R. A.; Narducci, R.; Ercolani, G.; Antonaroli, S.; Sgreccia, E.; Pasquini, L.; Knauth, P.; Di Vona, M. L., Alkaline stability of model anion exchange membranes based on poly(phenylene oxide) (PPO) with grafted quaternary ammonium groups: Influence of the functionalization route. Polymer 2019, 185, 121931.

14. Kreuer, K. D.; Jannasch, P., A practical method for measuring the ion exchange capacity decrease of hydroxide exchange membranes during intrinsic degradation. Journal of Power Sources 2018, 375, 361-366. 15. Jasti, A.; Prakash, S.; Shahi, V. K., Stable and hydroxide ion conductive membranes for fuel cell applications: Chloromethyaltion and amination of poly(ether ether ketone). Journal of Membrane Science 2013, 428, 470-479.

16. Li, N. W.; Leng, Y. J.; Hickner, M. A.; Wang, C. Y., Highly Stable, Anion Conductive, CombShaped Copolymers for Alkaline Fuel Cells. Journal of the American Chemical Society 2013, 135, 10124-10133. 17. Li, N. W.; Wang, L. Z.; Hickner, M., Cross-linked comb-shaped anion exchange membranes with high base stability. Chemical Communications 2014, 50, 4092-4095.

18. Dang, H. S.; Jannasch, P., Exploring Different Cationic Alkyl Side Chain Designs for Enhanced Alkaline Stability and Hydroxide Ion Conductivity of Anion-Exchange Membranes. Macromolecules 2015, $48,5742-5751$.

19. Varcoe, J. R.; Slade, R. C. T., Prospects for alkaline anion-exchange membranes in low temperature fuel cells. Fuel Cells 2005, 5, 187-200.

20. Jagur-Grodzinski, J., Polymeric materials for fuel cells: concise review of recent studies. Polymers for Advanced Technologies 2007, 18, 785-799.

21. Marino, M. G.; Kreuer, K. D., Alkaline Stability of Quaternary Ammonium Cations for Alkaline Fuel Cell Membranes and Ionic Liquids. Chemsuschem 2015, 8, 513-523. 
22. Pan, Y.; Zhang, Q. D.; Yan, X. M.; Liu, J. F.; Xu, X. W.; Wang, T. Y.; El Hamouti, I.; Ruan, X. H.; Hao, C.; He, G. H., Hydrophilic side chain assisting continuous ion-conducting channels for anion exchange membranes. Journal of Membrane Science 2018, 552, 286-294.

23. Narducci, R.; Ercolani, G.; Becerra-Arciniegas, R. A.; Pasquini, L.; Knauth, P.; Di Vona, M. L., "Intrinsic" Anion Exchange Polymers through the Dissociation of Strong Basic Groups: PPO with Grafted Bicyclic Guanidines. Membranes 2019, 9.

24. Bauer, B.; Strathmann, H.; Effenberger, F., Anion-exchange membranes with improved alkaline stability. Desalination 1990, 79, 125-144.

25. Zadok, I.; Dekel, D. R.; Srebnik, S., Effect of Ammonium Cations on the Diffusivity and Structure of Hydroxide Ions in Low Hydration Media. Journal of Physical Chemistry C 2019, 123, 27355 27362.

26. Zhang, M.; Liu, J. L.; Wang, Y. G.; An, L. A.; Guiver, M. D.; Li, N. W., Highly stable anion exchange membranes based on quaternized polypropylene. Journal of Materials Chemistry A 2015, 3, 12284 12296.

27. Mohanty, A. D.; Tignor, S. E.; Krause, J. A.; Choe, Y. K.; Bae, C., Systematic Alkaline Stability Study of Polymer Backbones for Anion Exchange Membrane Applications. Macromolecules 2016, 49, 33613372 .

28. Lin, C. X.; Wang, X. Q.; Hu, E. N.; Yang, Q.; Zhang, Q. G.; Zhu, A. M.; Liu, Q. L., Quaternized triblock polymer anion exchange membranes with enhanced alkaline stability. J. Membr. Sci. 2017, 541, 358366.

29. Pan, J.; Han, J. J.; Zhu, L.; Hickner, M. A., Cationic Side-Chain Attachment to Poly(Phenylene Oxide) Backbones for Chemically Stable and Conductive Anion Exchange Membranes. Chemistry of Materials 2017, 29, 5321-5330.

30. $\quad$ Long, H.; Kim, K.; Pivovar, B. S., Hydroxide Degradation Pathways for Substituted Trimethylammonium Cations: A DFT Study. Journal of Physical Chemistry C 2012, 116, 9419-9426.

31. Liu, L.; Chu, X. M.; Liao, J. Y.; Huang, Y. D.; Li, Y.; Ge, Z. Y.; Hickner, M. A.; Li, N. W., Tuning the properties of poly(2,6-dimethyl-1,4-phenylene oxide) anion exchange membranes and their performance in H-2/O-2 fuel cells. Energy \& Environmental Science 2018, 11, 435-446.

32. Zhu, L.; Yu, X. D.; Hickner, M. A., Exploring backbone-cation alkyl spacers for multi-cation side chain anion exchange membranes. Journal of Power Sources 2018, 375, 433-441.

33. Di Vona, M. L.; Casciola, M.; Donnadio, A.; Nocchetti, M.; Pasquini, L.; Narducci, R.; Knauth, P., Anionic conducting composite membranes based on aromatic polymer and layered double hydroxides. Int. J. Hydrogen Energy 2017, 42, 3197-3205.

34. Pizzoferrato, R.; Ciotta, E.; Ferrari, I. V.; Narducci, R.; Pasquini, L.; Varone, A.; Richetta, M.; Antonaroli, S.; Braglia, M.; Knauth, P.; Di Vona, M. L., Layered Double Hydroxides Containing an Ionic Liquid: Ionic Conductivity and Use in Composite Anion Exchange Membranes. Chemelectrochem 2018, 5, 2781-2788.

35. Derbali, Z.; Fahs, A.; Chailan, J. F.; Ferrari, I. V.; Di Vona, M. L.; Knauth, P., Composite anion exchange membranes with functionalized hydrophilic or hydrophobic titanium dioxide. Int. J. Hydrogen Energy 2017, 42, 19178-19189.

36. Sun, Z.; Lin, B. C.; Yan, F., Anion-Exchange Membranes for Alkaline Fuel-Cell Applications: The Effects of Cations. Chemsuschem 2018, 11, 58-70.

37. Liu, L.; Li, Q.; Dai, J. W.; Wang, H.; Jin, B. K.; Bai, R. K., A facile strategy for the synthesis of guanidinium-functionalized polymer as alkaline anion exchange membrane with improved alkaline stability. J. Membr. Sci. 2014, 453, 52-60.

38. Chalk, A. J.; Hay, A. S., Direct metalation of poly(2,6-dimethyl-1,4-phenylene ether). Journal of Polymer Science Part A-1: Polymer Chemistry 1969, 7, 691-705.

39. Wang, Z. Y.; Parrondo, J.; Ramani, V., Alkaline Stability of Poly(Phenylene Oxide) Based Anion Exchange Membranes Containing Imidazolium Cations. J. Electrochem. Soc. 2016, 163, F824-F831.

40. Pasquini, L.; Di Vona, M. L.; Knauth, P., Effects of anion substitution on hydration, ionic conductivity and mechanical properties of anion-exchange membranes. New J. Chem. 2016, 40, 3671-3676.

41. Liang, M., Poly(phenylene oxide). 2011; Vol. 3.

42. Arges, C. G.; Wang, L. H.; Jung, M. S.; Ramani, V., Mechanically Stable Poly(arylene ether) Anion Exchange Membranes Prepared from Commercially Available Polymers for Alkaline Electrochemical Devices. Journal of the Electrochemical Society 2015, 162, F686-F693. 
43. Parrondo, J.; Jung, M. S. J.; Wang, Z. Y.; Arges, C. G.; Ramani, V., Synthesis and Alkaline Stability of Solubilized Anion Exchange Membrane Binders Based on Poly(phenylene oxide) Functionalized with Quaternary Ammonium Groups via a Hexyl Spacer. Journal of the Electrochemical Society 2015, 162, F1236F1242.

44. Teresa Perez-Prior, M.; Urena, N.; Tannenberg, M.; del Rio, C.; Levenfeld, B., DABCOfunctionalized polysulfones as anion-exchange membranes for fuel cell applications: Effect of crosslinking. Journal of Polymer Science Part B-Polymer Physics 2017, 55, 1326-1336.

45. Kortüm, G., Treatise on Electrochemistry, 2nd edition. 2nd ed.; Elsevier: Amsterdam, New York, 1965.

46. Hamann, C. H.; Hamnett, A.; Vielstich, W., Electrochemistry. 2nd Edition ed.; Wiley-VCH: Weinheim, 2007.

47. Braglia, M.; Ferrari, I. V.; Pasquini, L.; Djenizian, T.; Sette, M.; Di Vona, M. L.; Knauth, P., Electrochemical synthesis of thin, dense, and conformal anion exchange membranes with quaternary ammonium groups. Electrochim. Acta 2018, 265, 78-88.

48. Pasquini, L.; Knauth, P.; Pelzer, K.; Di Vona, M. L., Anion-conducting sulfaminated aromatic polymers by acid functionalization. Rsc Advances 2015, 5, 56636-56644.

49. Narducci, R.; Pasquini, L.; Chailan, J. F.; Knauth, P.; Di Vona, M. L., Low-Permeability Poly(ether Ether Ketone)-Based Ampholytic Membranes. Chempluschem 2016, 81, 550-556.

50. $\quad$ Narducci, R.; Chailan, J. F.; Fahs, A.; Pasquini, L.; Di Vona, M. L.; Knauth, P., Mechanical Properties of Anion Exchange Membranes by Combination of Tensile Stress-Strain Tests and Dynamic Mechanical Analysis. Journal of Polymer Science Part B-Polymer Physics 2016, 54, 1180-1187.

51. Sgreccia, E.; Di Vona, M. L.; Licoccia, S.; Sganappa, M.; Casciola, M.; Chailan, J. F.; Knauth, P., Self-assembled nanocomposite organic-inorganic proton conducting sulfonated poly-ether-ether-ketone (SPEEK)-based membranes: Optimized mechanical, thermal and electrical properties. J. Power Sources 2009, 192, 353-359.

52. Li, X. G., High-resolution thermogravimetry of poly(2,6-dimethyl-1,4-phenylene oxide). Journal of Applied Polymer Science 1999, 71, 1887-1892.

53. Ehlers, G. F. L.; Fisch, K. R.; Powell, W. R., Thermal degradation of polymers with phenylene units in the chain. I. Polyphenylenes and poly(phenylene oxides). Journal of Polymer Science Part A-1: Polymer Chemistry 1969, 7, 2931-2953.

54. Tomoi, M.; Yamaguchi, K.; Ando, R.; Kantake, Y.; Aosaki, Y.; Kubota, H., Synthesis and thermal stability of novel anion exchange resins with spacer chains. J. Appl. Polym. Sci. 1997, 64, 1161-1167.

55. Streitwieser, A., Solvolytic Displacement Reactions. Literary Licensing, LLC: 2012. 
TOC Graphic

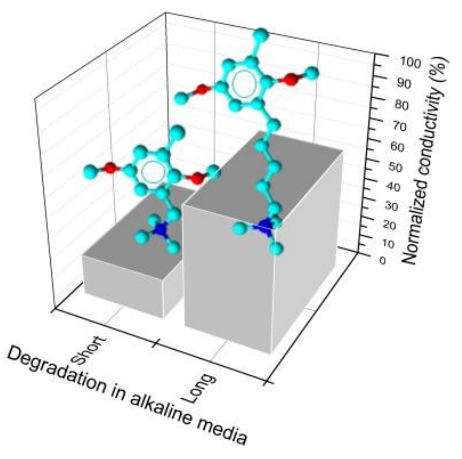

